\title{
Vascular Risk Factors and Diabetic Neuropathy
}

\author{
Solomon Tesfaye, M.D., Nish Chaturvedi, M.D., Simon E.M. Eaton, D.M., \\ John D. Ward, M.D., Christos Manes, M.D., Constantin Ionescu-Tirgoviste, M.D., \\ Daniel R. Witte, Ph.D., and John H. Fuller, M.A., \\ for the EURODIAB Prospective Complications Study Group*
}

ABSTRACT

BACK GROUN D

Other than glycemic control, there are no treatments for diabetic neuropathy. Thus, identifying potentially modifiable risk factors for neuropathy is crucial. We studied risk factors for the development of distal symmetric neuropathy in 1172 patients with type 1 diabetes mellitus from 31 centers participating in the European Diabetes (EURODIAB) Prospective Complications Study.

\section{METHODS}

Neuropathy was assessed at baseline (1989 to 1991) and at follow-up (1997 to 1999), with a mean $( \pm S D)$ follow-up of $7.3 \pm 0.6$ years. A standardized protocol included clinical evaluation, quantitative sensory testing, and autonomic-function tests. Serum lipids and lipoproteins, glycosylated hemoglobin, and the urinary albumin excretion rate were measured in a central laboratory.

\section{RESULTS}

At follow-up, neuropathy had developed in 276 of 1172 patients without neuropathy at baseline (23.5 percent). The cumulative incidence of neuropathy was related to the glycosylated hemoglobin value and the duration of diabetes. After adjustment for these factors, we found that higher levels of total and low-density lipoprotein cholesterol and triglycerides, a higher body-mass index, higher von Willebrand factor levels and urinary albumin excretion rate, hypertension, and smoking were all significantly associated with the cumulative incidence of neuropathy. After adjustment for other risk factors and diabetic complications, we found that duration of diabetes, current glycosylated hemoglobin value, change in glycosylated hemoglobin value during the follow-up period, body-mass index, and smoking remained independently associated with the incidence of neuropathy. Cardiovascular disease at baseline was associated with double the risk of neuropathy, independent of cardiovascular risk factors.

\section{CONCLUSIONS}

This prospective study indicates that, apart from glycemic control, the incidence of neuropathy is associated with potentially modifiable cardiovascular risk factors, including a raised triglyceride level, body-mass index, smoking, and hypertension.

From the Diabetes Research Unit, Royal Hallamshire Hospital, Sheffield, United Kingdom (S.T., S.E.M.E., J.D.W.); the Department of Epidemiology and Public Health, Faculty of Medicine, Imperial College of Science, Technology and Medicine, London (N.C.); the Department of Internal Medicine and Diabetic Center, Papageorgiou General Teaching Hospital, Thessaloniki, Greece (C.M.); the Institute of Diabetes, Nutrition, and Metabolic Diseases, Bucharest, Romania (C.I.-T.); and EURODIAB, Department of Epidemiology and Public Health, Royal Free and University College Medical School, London (D.R.W., J.H.F.). Address reprint requests to Dr. Tesfaye at the Diabetes Research Unit, Royal Hallamshire Hospital, Sheffield S10 2JF, United Kingdom, or at solomon. tesfaye@sth.nhs.uk.

*The investigators in the European Diabetes (EURODIAB) Prospective Complications Study Group are listed in the Appendix.

N EnglJ Med 2005;352:341-50. Copyright $\odot 2005$ Massachusetts Medical Society. 
$\mathrm{D}$ IABETIC NEUROPATHY IS A COMMON cause of morbidity and death among patients with diabetes, generating a huge economic burden. ${ }^{1}$ Apart from tight glycemic control, no other evidence-based treatments are known to ameliorate or prevent neuropathy.

The duration and level of hyperglycemia are important determinants of microvascular complications of diabetes, including neuropathy. ${ }^{2}$ The relative effect of cardiovascular risk factors specifically associated with diabetes (e.g., hypertension, dyslipidemia, and increased weight) or not associated with diabetes (smoking) on the development of neuropathy are incompletely elucidated. The Diabetes Control and Complications Trial (DCCT) reported a 60 percent reduction in neuropathy in the intensively treated groups after five years, ${ }^{2}$ but the cumulative incidence of neuropathy (15 to 21 percent) and abnormal nerve conduction (40 to 52 percent) remained substantial. Such findings suggest that neuropathy can develop, despite intensive control of the glucose level. ${ }^{2}$ Thus, risk factors besides hyperglycemia are probably involved in the evolution of neuropathy. Identifying them, particularly if they are modifiable, might lead to new risk-reduction strategies. The European Diabetes (EURODIAB) Prospective Complications Study aimed to define and assess the relative importance of other, potentially modifiable factors that increase the risk of distal symmetric neuropathy in patients with type 1 diabetes mellitus.

\section{METHODS}

\section{PATIENTS AND BASELINE INVESTIGATIONS}

The baseline examination included 3250 patients (1668 men and 1582 women; mean [ \pm SD] age, $32.7 \pm 10.2$ years; mean duration of diabetes, $14.7 \pm$ 9.3 years). ${ }^{3}$ These patients were randomly selected in a stratified manner from 31 diabetes clinics across Europe. Selection criteria and methods have been described previously. ${ }^{3}$ Written informed consent was obtained from all patients, and the institutional review board at each center approved the study. Trained physicians performed all measurements with standardized procedures and equipment according to a predefined protocol. Baseline examinations were conducted from 1989 to 1991, and follow-up examinations from 1997 to 1999.

Baseline blood samples, obtained after an overnight fast, if possible, were sent to central laboratories. Measurements included total cholesterol, high- density lipoprotein (HDL) cholesterol, and triglycerides. ${ }^{4-6}$ Levels of low-density lipoprotein (LDL) cholesterol were calculated. ${ }^{7}$ The reference range for glycosylated hemoglobin was 2.9 to 4.8 percent. ${ }^{8}$ In order to compare the results with those of the DCCT, measured glycosylated hemoglobin values were converted as previously reported (DCCT glycosylated hemoglobin $=[1.0289 \times$ the glycosylated hemoglobin measurements for this study]+ 1.5263). ${ }^{9}$ DCCT-converted glycosylated hemoglobin values were used in all further analyses.

Glycosylated hemoglobin values, measured centrally according to the follow-up protocol, were available for 1119 of 1172 patients (95.5 percent). Additional glycosylated hemoglobin values, determined at one to eight (median, five) routine interim visits (measured and standardized according to center) between baseline and the final follow-up visit, were available for 794 participants (67.7 percent). All available glycosylated hemoglobin measurements were included in estimates of the change in glycosylated hemoglobin during follow-up. Baseline and final follow-up glycosylated hemoglobin values were standardized for the entire group. Linear regression for each patient provided the change in glycosylated hemoglobin per patient per year of follow-up and was included in the analyses to assess a possible association with neuropathy beyond the baseline glycosylated hemoglobin value.

\section{ASSESSMENT AND DEFINITION OF DIABETIC COMPLICATIONS}

The urinary albumin excretion rate was measured from a single 24-hour urine collection. ${ }^{10} \mathrm{~A}$ urinary albumin excretion rate of 20 to $200 \mu \mathrm{g}$ per minute was defined as microalbuminuria; a rate greater than $200 \mu \mathrm{g}$ per minute was defined as macroalbuminuria.

The presence and severity of diabetic retinopathy were assessed from retinal photographs (two fields per eye) obtained with a wide-angle camera and scored centrally by one expert in reading changes of retinopathy. ${ }^{11}$ Retinopathy was classified as nonproliferative (background) or proliferative.

Cardiovascular disease was defined as either a history of physician-diagnosed cardiovascular disease (e.g., previous myocardial infarction, angina, coronary-artery bypass grafting, or stroke) or ischemic changes detected on a 12-lead electrocardiogram (classified by two observers according to the Minnesota code). ${ }^{12}$

To assess the role of insulin resistance, an esti- 
mated glucose disposal rate was calculated on the basis of the waist-to-hip ratio, the presence of hypertension, and the glycosylated hemoglobin value. ${ }^{13}$ Fibrinogen and von Willebrand factor were also measured. ${ }^{14}$

\section{ASSESSMENT OF DISTAL SYMMETRIC POLYNEUROPATHY}

Physicians experienced in taking a neurologic history assessed patients for distal symmetric polyneuropathy. Patients with features suggesting other forms of diabetic neuropathy or polyneuropathy due to causes other than diabetes were excluded.

\section{SYMPTOMS AND SIGNS OF NEUROPATHY}

The presence or absence of the following symptoms within the previous six months was ascertained: "asleep" numbness or "dead feeling" in the feet, a prickling sensation in the feet, deep aching or burning pains in the legs, unusual difficulty in climbing stairs, difficulty with bladder control, and nocturnal diarrhea. Symptoms were evaluated carefully to rule out other causes. In addition, reflexes of the ankle and knee tendons were assessed, with reinforcement if necessary.

\section{PERCEPTION OF VIBRATION}

The threshold of perception of vibration was measured by centrally calibrated biothesiometers (Biomedical). ${ }^{15}$ Three readings on the right big toe and right medial malleolus were obtained and averaged for the analysis.

\section{AUTONOMIC FUNCTION}

Autonomic function was assessed according to two cardiovascular reflex responses after the patients had rested in a supine position for at least five minutes - a change in heart rate and a change in systolic blood pressure on standing, as determined with a Hawksley random-zero sphygmomanometer. The $\mathrm{RR}$ ratio was calculated by one observer. The $R R$ ratio is the ratio of the longest electrocardiographic RR interval between the 28th and 32nd beats after standing to the shortest interval between the 13th and 17th beats.

\section{DEFINITION OF NEUROPATHY}

Neuropathy was diagnosed in patients with two or more of the following four measures: the presence of one or more symptoms, the absence of two or more reflexes of the ankle or knee tendons, a vibration-perception threshold that was abnormal for the patient's age, ${ }^{15}$ and abnormal autonomic function (loss of heart rate variability with an RR ratio of less than 1.04, postural hypotension with a fall in systolic blood pressure of $20 \mathrm{~mm} \mathrm{Hg}$ or more, or both). ${ }^{16}$ "Pure" peripheral neuropathy was defined as distal neuropathy without autonomic symptoms or abnormal autonomic-function tests.

The cutoff points and the definition of neuropathy were established before any examination of the outcome data. The four criteria were evaluated at the same times (the day of the baseline visit and the day of the follow-up visit) for each patient.

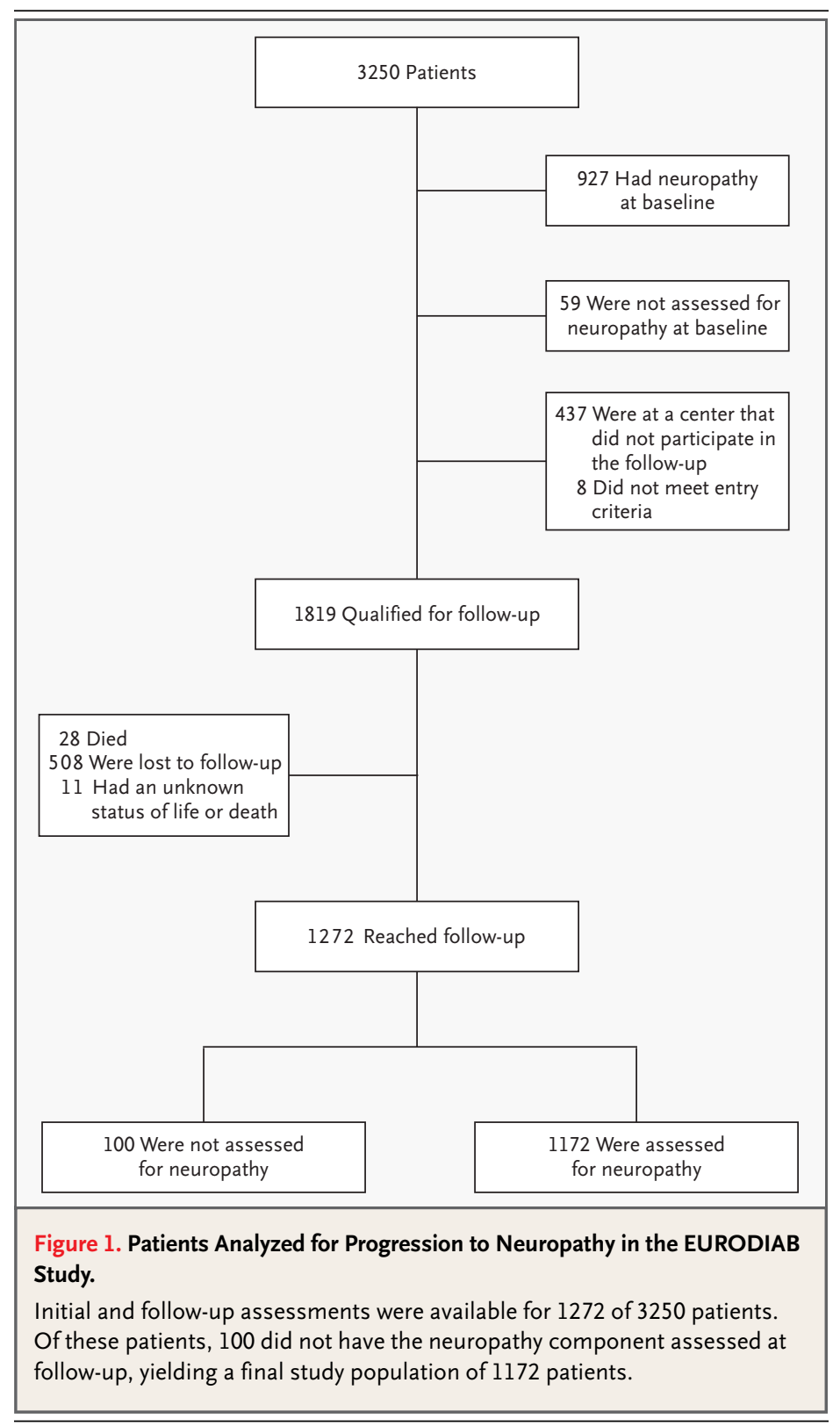


Of 3250 patients examined, 927 had neuropathy at baseline, ${ }^{17}$ whereas 1172 patients without neuropathy at baseline had neuropathy assessed at follow-up (Fig. 1). Baseline investigations and assessment of neuropathy were repeated after a mean of 7.3 years of follow-up.

\section{STATISTICAL ANALYSIS}

Statistical analyses were performed with Stata software (version 7.0). The characteristics of patients who did and those who did not undergo assessment for neuropathy were compared with the use of Student's t-test or the Mann-Whitney U test where appropriate. The possibility of a threshold effect in the relation between glycosylated hemoglobin values and the risk of neuropathy was evaluated by comparing the linear and exponential trend lines according to quintiles of glycosylated hemoglobin, as previously reported. ${ }^{9,18}$ The relation between risk factors and the incidence of neuropathy was analyzed with the use of logistic-regression models. Odds ratios for dichotomous variables express the risk of neuropathy for patients with the risk factors as compared with those without the risk factors.
Odds ratios for continuous risk factors were standardized, thus expressing the risk associated with a 1-SD increase in the continuous risk factors. All logistic-regression models were adjusted for the duration of diabetes and glycosylated hemoglobin values. The relation between the change in glycosylated hemoglobin values and the incidence of neuropathy was assessed with the use of logistic regression, with adjustments for potential confounders. The odds ratio for the incidence of neuropathy associated with each increase of one quintile in the glycosylated hemoglobin value, as compared with the lowest quintile (the reference category), was also assessed.

All relevant risk factors were included in a multivariate logistic-regression model to calculate mutually adjusted, standardized odds ratios (Model 1). In addition, complications of diabetes were added to the model (Model 2).

We used logistic-regression models to assess the development of neuropathy during follow-up, rather than an analysis of failure time (time to diagnosis of neuropathy) for current-status data, because there was little variation in follow-up time (mean,

\begin{tabular}{|c|c|c|c|}
\hline \multirow[t]{2}{*}{ Variable } & \multicolumn{2}{|c|}{ Assessed for Neuropathy at Follow-up } & \multirow[t]{2}{*}{ P Value } \\
\hline & No & Yes & \\
\hline No. of patients & 647 & 1172 & \\
\hline Age (yr) & $30.7 \pm 9.1$ & $30.7 \pm 8.8$ & 0.91 \\
\hline Duration of diabetes (yr) & $12.7 \pm 8.5$ & $12.4 \pm 8.1$ & 0.45 \\
\hline Glycosylated hemoglobin (\% of hemoglobin) & $8.3 \pm 1.9$ & $8.0 \pm 1.8$ & 0.01 \\
\hline Insulin dose per kg of body weight (IU) & $0.7 \pm 0.2$ & $0.7 \pm 0.2$ & 0.55 \\
\hline Systolic blood pressure $(\mathrm{mm} \mathrm{Hg}) \dagger$ & $118.0(96,148)$ & $117.0(96,142)$ & 0.03 \\
\hline Diastolic blood pressure $(\mathrm{mm} \mathrm{Hg}) \dagger$ & $74.0(57,92)$ & $74.0(58,91)$ & 0.95 \\
\hline Weight (kg) & $66.7 \pm 10.6$ & $66.8 \pm 10.5$ & 0.85 \\
\hline Body-mass indext & $23.3 \pm 2.7$ & $23.4 \pm 2.7$ & 0.58 \\
\hline Waist-to-hip ratio & $0.8 \pm 0.1$ & $0.8 \pm 0.1$ & 0.64 \\
\hline Albumin excretion rate $(\mu \mathrm{g} / \mathrm{min})$ & $9.5(3.2,148.2)$ & $9.9(3.3,147.1)$ & 0.32 \\
\hline Total cholesterol (mmol/liter) & $5.28 \pm 1.04$ & $5.16 \pm 1.05$ & 0.02 \\
\hline Triglycerides (mmol/liter) & $0.90(0.48,2.22)$ & $0.86(0.48,2.20)$ & 0.03 \\
\hline von Willebrand factor $(\mathrm{U} / \mathrm{ml})$ & $1.08 \pm(0.51,1.95)$ & $1.11(0.55,2.21)$ & 0.07 \\
\hline
\end{tabular}

* Plus-minus values are means \pm SD. Alternatively, in cases of skewed distributions, data are medians (5th percentile, 95th percentile). $\mathrm{P}$ values are derived from Student's t-test for data normally distributed or, in cases of skewed distributions, from a Mann-Whitney $U$ test. To convert values for cholesterol to milligrams per deciliter, divide by 0.02586 . To convert values for triglycerides to milligrams per deciliter, divide by 0.01129 .

$\dagger$ The blood-pressure data exclude patients who were undergoing antihypertensive therapy.

7 The body-mass index is the weight in kilograms divided by the square of the height in meters. 
$7.3 \pm 0.6$ years); the response is therefore the cumulative incidence of neuropathy during the followup period. All $P$ values are two-sided.

\section{RES U LTS}

BASELINE CHARACTERISTICS OF THE PATIENTS WITHOUT NEUROPATHY AT BASELINE

Table 1 compares baseline data among the 1819 patients without neuropathy at baseline. Those who were lost to follow-up or died or in whom neuropathy was not assessed (647 patients) had higher baseline glycosylated hemoglobin, systolic blood pressure, total cholesterol, and triglyceride levels. Of the remaining 1172 patients without neuropathy at baseline, neuropathy had developed in 276 at follow-up - a cumulative incidence of neuropathy of 23.5 percent. There was little variation in the incidence of defining variables: symptoms of neuropathy developed in 24.4 percent of patients, absent reflexes in 20.5 percent, abnormal vibration-perception threshold in 20.4 percent, and abnormal autonomic-function results in 17.3 percent. There were no significant differences between centers in the in-

\begin{tabular}{|c|c|c|c|}
\hline Variable & $\begin{array}{l}\text { Progression } \\
\text { to Neuropathy }\end{array}$ & $\begin{array}{l}\text { No Progression } \\
\text { to Neuropathy }\end{array}$ & $P$ Value \\
\hline No. of patients & 276 & 896 & \\
\hline Age (yr) & $33.6 \pm 10.0$ & $29.8 \pm 8.1$ & $<0.001$ \\
\hline Duration of diabetes (yr) & $14.9 \pm 8.9$ & $11.6 \pm 7.6$ & $<0.001$ \\
\hline Male sex (\%) & 48.6 & 51.1 & 0.46 \\
\hline History of smoking (\%) & 53.6 & 41.6 & $<0.001$ \\
\hline Height $(\mathrm{cm})$ & $169 \pm 9$ & $169 \pm 9$ & 0.66 \\
\hline Weight (kg) & $68.9 \pm 11.1$ & $66.1 \pm 10.2$ & $<0.001$ \\
\hline Body-mass index & $24.2 \pm 3.0$ & $23.1 \pm 2.5$ & $<0.001$ \\
\hline Waist-to-hip ratio & $0.8 \pm 0.1$ & $0.8 \pm 0.1$ & 0.2 \\
\hline Glycosylated hemoglobin (\% of hemoglobin) & $8.4 \pm 1.9$ & $7.9 \pm 1.8$ & $<0.001$ \\
\hline Insulin dose per kg of body weight (IU) & $0.7 \pm 0.2$ & $0.7 \pm 0.2$ & 0.8 \\
\hline Estimated glucose disposal rate $(\mathrm{mg} / \mathrm{kg} / \mathrm{min})$ & $8.46 \pm 0.14$ & $9.24 \pm 0.06$ & $<0.001$ \\
\hline Total cholesterol (mmol/liter) & $5.45 \pm 1.13$ & $5.07 \pm 1.01$ & $<0.001$ \\
\hline Low-density lipoprotein cholesterol (mmol/liter) & $3.44 \pm 0.99$ & $3.15 \pm 0.91$ & $<0.001$ \\
\hline High-density lipoprotein cholesterol (mmol/liter) & $1.48 \pm 0.42$ & $1.52 \pm 0.43$ & 0.12 \\
\hline Triglycerides (mmol/liter) & $0.98(0.54,2.89)$ & $0.83(0.48,2.08)$ & $<0.001$ \\
\hline Fibrinogen (g/liter) & $3.17 \pm 0.89$ & $3.14 \pm 0.86$ & 0.71 \\
\hline von Willebrand factor $(\mathrm{U} / \mathrm{ml})$ & $1.20(0.63,2.28)$ & $1.08(0.53,2.17)$ & 0.004 \\
\hline Systolic blood pressure $(\mathrm{mm} \mathrm{Hg}) \dagger$ & $118(96,153)$ & $116(96,140)$ & 0.48 \\
\hline Diastolic blood pressure $(\mathrm{mm} \mathrm{Hg}) \dagger$ & $75(56,90)$ & $73(58,92)$ & 0.52 \\
\hline Albumin excretion rate $(\mu \mathrm{g} / \mathrm{min})$ & $11.6(3.6,398.0)$ & $9.5(3.1,78.4)$ & $<0.001$ \\
\hline Hypertension (\%) & 25.1 & 14.9 & $<0.001$ \\
\hline Macroalbuminuria (\%) & 7.2 & 2.7 & 0.006 \\
\hline Microalbuminuria or macroalbuminuria (\%) & 31.1 & 20.1 & $<0.001$ \\
\hline Any retinopathy (\%) & 51.2 & 31.9 & $<0.001$ \\
\hline Proliferative retinopathy (\%) & 6.2 & 2.8 & 0.03 \\
\hline History of cardiovascular disease (\%) & 12.8 & 4.7 & $<0.001$ \\
\hline
\end{tabular}

* Plus-minus values are means \pm SD. Alternatively, in cases of skewed distributions, data are medians (5th percentile, 95th percentile). $P$ values are derived from Student's t-test or, in cases of skewed distributions, from a Mann-Whitney U test. To convert values for cholesterol to milligrams per deciliter, divide by 0.02586 . To convert values for triglycerides to milligrams per deciliter, divide by 0.01129 .

$\dagger$ The blood-pressure data exclude patients who were undergoing antihypertensive therapy. 
cidence of neuropathy. At baseline, 570 of the 927 subjects defined as having neuropathy (61.5 percent) had an abnormal measurement of the vibration-perception threshold.

\section{BASELINE CHARACTERISTICS ACCORDING TO THE INCIDENCE OF NEUROPATHY}

Table 2 shows baseline characteristics of the study population grouped according to whether neuropathy did or did not develop during the study. Patients in whom neuropathy developed were on average 3.8 years older, had had diabetes for 3.3 years longer, and had poorer blood glucose control (a glycosylated hemoglobin value 0.5 percent higher) at baseline than those in whom neuropathy did not develop.

In unadjusted comparisons, patients in whom neuropathy developed also had higher baseline levels of total and LDL cholesterol and fasting triglycerides, a higher body-mass index, higher von Willebrand factor levels and albumin excretion rate,

\begin{tabular}{|c|c|c|}
\hline Variable & $\begin{array}{c}\text { Odds Ratio } \\
\text { (95\% Cl) }\end{array}$ & P Value \\
\hline Total cholesterol (mmol/liter) & $1.26(1.10-1.45)$ & 0.001 \\
\hline Low-density lipoprotein cholesterol (mmol/liter) & $1.22(1.03-1.45)$ & 0.02 \\
\hline Triglycerides (mmol/liter) & $1.35(1.16-1.57)$ & $<0.001$ \\
\hline von Willebrand factor $(\mathrm{U} / \mathrm{ml}) \dagger$ & $1.20(1.02-1.42)$ & 0.03 \\
\hline Weight (kg) & $1.34(1.17-1.54)$ & $<0.001$ \\
\hline Body-mass index & $1.40(1.22-1.61)$ & $<0.001$ \\
\hline Waist-to-hip ratio & $1.06(0.93-1.22)$ & 0.4 \\
\hline Estimated glucose disposal rate $(\mathrm{mg} / \mathrm{kg} / \mathrm{min})$ & $1.37(1.08-1.73)$ & 0.01 \\
\hline Albumin excretion rate $(\mu \mathrm{g} / \mathrm{min}) \dagger$ & $1.25(1.10-1.43)$ & 0.001 \\
\hline Insulin dose per kg of body weight (IU) & $1.09(0.95-1.26)$ & 0.2 \\
\hline History of smoking & $1.55(1.17-2.04)$ & $<0.001$ \\
\hline Hypertension & $1.92(1.30-2.82)$ & $<0.001$ \\
\hline Macroalbuminuria & $2.08(1.11-3.90)$ & 0.02 \\
\hline Microalbuminuria or macroalbuminuria & $1.48(1.07-2.04)$ & 0.02 \\
\hline Proliferative retinopathy & $1.54(0.79-2.98)$ & 0.2 \\
\hline Any retinopathy & $1.70(1.19-2.43)$ & 0.003 \\
\hline Cardiovascular disease & $2.74(1.68-4.49)$ & $<0.001$ \\
\hline
\end{tabular}

* Standardized odds ratios are expressed per SD increase in each continuous risk factor. Odds ratios for dichotomous variables have as a reference group those patients without the respective risk factor. $\mathrm{Cl}$ denotes confidence interval. To convert values for cholesterol to milligrams per deciliter, divide by 0.02586 . To convert values for triglycerides to milligrams per deciliter, divide by 0.01129 .

$\dagger$ Log transformation was used. and a lower estimated glucose disposal rate. More patients in whom neuropathy developed had baseline hypertension, microalbuminuria or macroalbuminuria, any retinopathy, a history of cardiovascular disease, and a history of smoking.

There was no evidence of a significant threshold effect of glycosylated hemoglobin at baseline and progression to neuropathy. An abnormal vibrationperception threshold was present in 166 (60.1 percent) of the 276 patients in whom neuropathy developed.

\section{RISK FACTORS FOR NEUROPATHY AFTER ADJUSTMENT FOR GLYCOSYLATED HEMOGLOBIN AND DURATION OF DIABETES}

Adjustment for possible confounding by the two major known determinants of neuropathy - duration of diabetes and glycosylated hemoglobin value (Table 3) - attenuated or abolished some associations with progression to neuropathy. The risk factors that remained significantly associated with the development of neuropathy were baseline cardiovascular risk factors (body-mass index and levels of total cholesterol, LDL cholesterol, and triglycerides). The urinary albumin excretion rate at baseline and the von Willebrand factor level were also elevated in patients in whom neuropathy developed (Table 3), as was the insulin resistance (but the estimated glucose disposal rate was lower).

After adjustment for glycosylated hemoglobin value and duration of diabetes, we found that the presence of hypertension, albuminuria (either microalbuminuria or macroalbuminuria), any retinopathy, history of cardiovascular disease, and history of smoking at baseline were significantly associated with newly diagnosed neuropathy (odds ratio for microalbuminuria or macroalbuminuria, 1.48; and for history of cardiovascular disease, 2.74). Both former and current smoking at baseline were significantly related to neuropathy when included separately, with adjustment for glycosylated hemoglobin values and duration of diabetes. Since both smoking groups had similar risk, they are presented jointly.

\section{CHANGE IN GLYCOSYLATED HEMOGLOBIN LEVELS DURING FOLLOW-UP}

An increase in glycosylated hemoglobin was associated with an odds ratio of 1.45 (95 percent confidence interval, 1.23 to $1.72 ; \mathrm{P}<0.001)$, after adjustment for baseline glycosylated hemoglobin value and duration of diabetes. Figure 2 depicts the odds 
ratio for each quintile of change in the glycosylated hemoglobin value, as compared with the lowest quintile of change (the reference category), with adjustment for the baseline glycosylated hemoglobin value and duration of diabetes. The odds ratio for the development of neuropathy was 2.48 ( 95 percent confidence interval, 1.50 to 4.11 ) for patients with the highest rate of deterioration of glycosylated hemoglobin (the highest quintile).

\section{MULTIVARIATE MODELS}

In a multivariate logistic-regression model (Table 4, Model 1) that mutually adjusted for the presence of all other risk factors, we found that duration of diabetes, glycosylated hemoglobin value, change in glycosylated hemoglobin value, triglyceride level, body-mass index, history of smoking, and presence of hypertension at baseline remained significantly associated with the incidence of neuropathy. The relation between cholesterol level and the incidence of neuropathy in Model 1 did not reach statistical significance, and albumin excretion rate was unrelated to neuropathy. The strongest relation was with hypertension, which carried an odds ratio of 1.57. Addition of the estimated glucose disposal rate to this model did not materially change the odds ratios for the other variables, and the glucose disposal rate itself was not associated with newly diagnosed neuropathy (odds ratio, 0.99 ; 95 percent confidence interval, 0.90 to $1.08 ; \mathrm{P}=0.75$ ).

When complications of diabetes were added to the model (Table 4, Model 2), odds ratios for triglycerides and hypertension were not statistically significant. Duration of diabetes, glycosylated hemoglobin value, change in glycosylated hemoglobin value, body-mass index, and history of smoking remained significantly related to the incidence of neuropathy. In addition, the presence of cardiovascular disease at baseline was independently related to the incidence of neuropathy (odds ratio, 2.12). The relation between any retinopathy and neuropathy was insignificant $(\mathrm{P}=0.06)$ when change in the glycosylated hemoglobin value was included in the model but reached significance $(\mathrm{P}=0.04)$ when change in the glycosylated hemoglobin value was excluded.

Models 1 and 2 were repeated without autonomic symptoms and the results of autonomic-function tests. The only major difference in the results was that the relationship between hypertension and "pure" peripheral neuropathy was no longer statistically significant.

\section{I SCUSSION}

During a period of seven years, the incidence of neuropathy in the EURODIAB cohort of patients with type 1 diabetes was 23.5 percent, confirming the previously reported strong contributions of glycemic control and duration of diabetes to the risk of neuropathy. ${ }^{17,19,20}$ We observed that the rate of deterioration of glycemic control during follow-up contributed markedly to the risk of neuropathy, independently of the glycosylated hemoglobin value at baseline. Furthermore, cardiovascular risk factors, such as hypertension, smoking, obesity, and elevated triglyceride levels, and the presence of cardiovascular disease at baseline appear to be related to newly diagnosed neuropathy.

This study used a definition of neuropathy that was similar to that in other protocols, $, 21,22$ and 28.5 percent of patients had neuropathy at baseline,${ }^{17}$ a frequency similar to that observed in other studies. ${ }^{22}$ Of the patients with neuropathy at baseline, approximately 60 percent had an abnormal vibration-perception threshold. Moreover, 500 randomly selected subjects within the cohort underwent nerve-conduction studies of the arms and legs at follow-up; there was a significant relationship between the slowing of nerve conduction and the

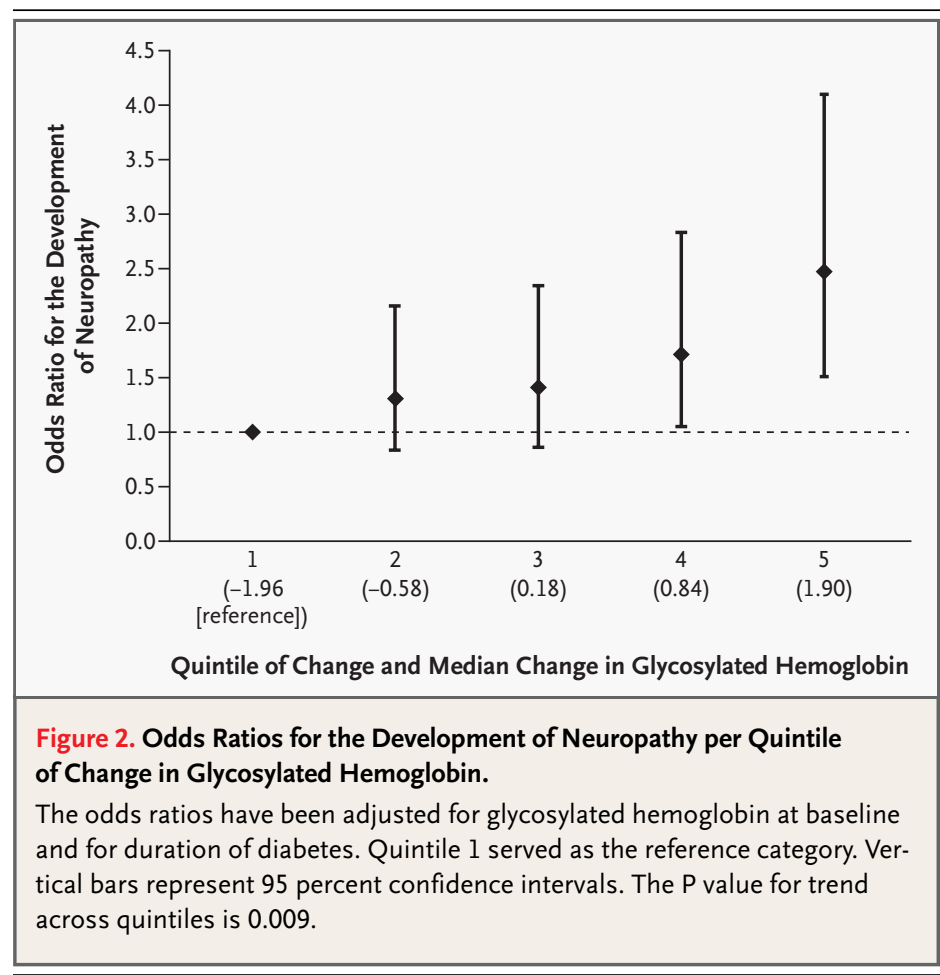




\begin{tabular}{|c|c|c|}
\hline \multicolumn{3}{|c|}{$\begin{array}{l}\text { Table 4. Odds Ratios for Associations between Key Risk Factors } \\
\text { and the Incidence of Diabetic Neuropathy with the Use of Two Logistic- } \\
\text { Regression Models." }\end{array}$} \\
\hline Variable & $\begin{array}{l}\text { Odds Ratio } \\
(95 \% \mathrm{CI})\end{array}$ & P Value \\
\hline \multicolumn{3}{|l|}{ Model $1 \dagger$} \\
\hline Duration of diabetes (yr) & $1.40(1.21-1.63)$ & $<0.001$ \\
\hline Glycosylated hemoglobin (\% of hemoglobin) & $1.48(1.23-1.79)$ & $<0.001$ \\
\hline $\begin{array}{l}\text { Change in glycosylated hemoglobin } \\
\text { (\% of hemoglobin) }\end{array}$ & $1.36(1.14-1.62)$ & 0.001 \\
\hline Triglycerides (mmol/liter) & $1.21(1.02-1.44)$ & 0.03 \\
\hline Total cholesterol (mmol/liter) & $1.15(0.98-1.35)$ & 0.08 \\
\hline Body-mass index & $1.27(1.09-1.47)$ & $<0.001$ \\
\hline History of smoking & $1.38(1.03-1.85)$ & 0.03 \\
\hline Hypertension & $1.57(1.03-2.39)$ & 0.03 \\
\hline Albumin excretion rate $(\mu \mathrm{g} / \mathrm{min})$ & $1.01(0.88-1.14)$ & 0.93 \\
\hline \multicolumn{3}{|l|}{ Model $2 \%$} \\
\hline Duration of diabetes (yr) & $1.25(1.03-1.51)$ & 0.02 \\
\hline Glycosylated hemoglobin (\% of hemoglobin) & $1.64(1.33-2.03)$ & $<0.001$ \\
\hline $\begin{array}{l}\text { Change in glycosylated hemoglobin } \\
\text { (\% of hemoglobin) }\end{array}$ & $1.44(1.17-1.77)$ & 0.001 \\
\hline Triglycerides (mmol/liter) & $1.17(0.97-1.41)$ & 0.10 \\
\hline Total cholesterol (mmol/liter) & $1.11(0.93-1.34)$ & 0.25 \\
\hline Body-mass index & $1.20(1.01-1.43)$ & 0.04 \\
\hline History of smoking & $1.68(1.20-2.36)$ & 0.003 \\
\hline Hypertension & $1.54(0.96-2.47)$ & 0.07 \\
\hline Cardiovascular disease & $2.12(1.16-3.86)$ & 0.01 \\
\hline Any retinopathy & $1.45(0.98-2.13)$ & 0.06 \\
\hline Albumin excretion rate $(\mu \mathrm{g} / \mathrm{min})$ & $1.02(0.89-1.18)$ & 0.76 \\
\hline
\end{tabular}

* Cl denotes confidence interval. To convert values for cholesterol to milligrams per deciliter, divide by 0.02586 . To convert values for triglycerides to milligrams per deciliter, divide by 0.01129 .

$\dagger$ Model 1 represents 1101 observations with urinary albumin excretion rate but without retinopathy and cardiovascular disease.

7 Model 2 represents 932 observations with urinary albumin excretion rate and complications of diabetes (retinopathy and cardiovascular disease).

number of abnormal criteria used to define neuropathy.

Assessing neuropathy involves measures that are prone to varying degrees of subjectivity or observer bias. However, these measurement errors are likely only to underestimate the statistical significance of the association between risk factors and disease.

Elucidating the risk factors for neuropathy is important, given the association between the risk factors and increased diabetes-related morbidity and mortality. ${ }^{23}$ Mortality in patients with neuropathy is high, and the cause of death is often coronary heart disease. ${ }^{23,24}$ Previous cross-sectional studies have reported associations between neuropathy and height, ${ }^{25}$ cigarette smoking, ${ }^{26}$ low levels of HDL cholesterol, ${ }^{19}$ and hypertension ${ }^{19,27}$ in addition to established risk factors, level of glycemia, and duration of diabetes. Hypertension was observed to be a strong risk factor for neuropathy in 463 young patients with type 1 diabetes. ${ }^{21} \mathrm{~A}$ follow-up of subjects with either type 1 or type 2 diabetes suggested that both type 1 and type 2 diabetes and markers of microvascular disease were associated with the severity of neuropathy. ${ }^{28}$

The baseline cross-sectional data in the present study ${ }^{17}$ are evidence of a strong association between neuropathy and other microvascular complications, suggesting a common pathogenic mechanism..$^{29-31}$ We excluded all patients with neuropathy at baseline in order to identify new cases, resulting in a less robust but still significant association.

Several of the risk factors associated with neuropathy in this study are markers of insulin resistance. Both an elevated triglyceride level and obesity are strong predictors of microalbuminuria and retinopathy in type 1 diabetes. ${ }^{9,18}$ Insulin resistance, present in type 1 diabetes, ${ }^{32}$ may be involved in the development of both microvascular and macrovascular complications. ${ }^{33,34}$ A potential link between insulin resistance and microvascular complications including neuropathy is their association with endothelial dysfunction. ${ }^{35}$ Other complications of diabetes linked to endothelial dysfunction may also predict the risk of microalbuminuria, ${ }^{18}$ retinopathy, ${ }^{9}$ and neuropathy. The patients in whom neuropathy developed had a lower estimated glucose disposal rate at baseline (higher insulin resistance). However, multivariate analysis indicates that obesity, glycemic control, and the level of triglycerides were more predictive individually as compared with the combined summary measure.

When autonomic symptoms and results of autonomic-function tests were excluded from the definition of neuropathy, the effect of hypertension on the incidence of neuropathy lost statistical significance. This is consistent with our previous report that systolic blood pressure was a risk factor for the development of cardiac autonomic neuropathy. ${ }^{36}$

Apart from the use of medication to induce glucose values approaching normoglycemia, no other treatments currently exist to reduce the progression to neuropathy. ${ }^{29}$ Aggressive treatment of hypertension is now standard clinical practice in the management of nephropathy and retinopathy, and the 
results of the present study make a case for clinical trials to confirm the efficacy of antihypertensive agents and possibly other strategies for cardiovascular risk reduction in slowing the progression of neuropathy.
The EURODIAB Prospective Complications Study was supported by grants from the Wellcome Trust, the European Union, and Diabetes UK.

Dr. Tesfaye reports having received consulting and lecture fees from Eli Lilly, consulting fees from AstraZeneca and Pfizer, and lecture fees from Takeda and GlaxoSmithKline.

APPENDIX

In addition to the authors, the following investigators participated in the EURODIAB Prospective Complications Study: Greece - B. Karamanos, A. Kofinis, K. Petrou (Hippokration Hospital, Athens); N. Papazoglou, C. Manes (General Hospital Papageorgiou of Thessaloniki, Thessaloniki); Italy - F. Giorgino, G. Picca, A. Angarano, G. De Pergola, L. Laviola, R. Giorgino (Endocrinologia e Malattie Metaboliche, DETO, Università Degli Studi di Bari, Bari); M. Songini, A. Casu, M. Pedron, S. Pintus, M. Fossarello (Ospedale San Michele, Cagliari); G. Pozza, R. Mangili, V. Asnaghi (Ospedale San Raffaele, Milan); F. Santeusanio, G. Rosi, V. D’Alessandro, C. Cagini, P. Bottini, G.P. Reboldi (Istituto di Patologia Medica, Policlinico, Perugia); R. Navalesi, G. Penno, S. Bandinelli, R. Miccoli, M. Nannipieri (Dipartimento di Endocrinologia e Metabolismo, Pisa); G. Ghirlanda, C. Saponara, P. Cotroneo, A. Manto, A. Minnella (Universita Cattolica del Sacro Cuore, Rome); M. Borra, P. Cavallo Perin, S. Giunti, G. Grassi, G.F. Pagano, M. Porta, R. Sivieri, F. Vitelli, D. Ferrari, M. Veglio (Dipartimento di Medicina Interna, Università di Torino and ASO CTO/CRF/Maria Adelaide, Turin); M. Muggeo, M. Iagulli (V Cattedra di Malattie del Metabolismo, Verona); Ireland - J.B. Ferriss, G. Grealy, D.O. Keefe (Cork Regional Hospital, Cork); Germany — M. Toeller, C. Arden (Diabetes Research Institute, Heinrich Heine University, Dusseldorf); E. Standl, B. Schaffler, H. Brand, A. Harms (City Hospital Schwabing, Munich); Belgium - R. Rottiers, C. Tuyttens, H. Priem (University Hospital of Ghent, Ghent); Finland - P. Ebeling, M. Kylliäinen, V.A. Koivisto (University Hospital of Helsinki, Helsinki); Poland - B. Idzior-Walus, J. Sieradzki, K. Cyganek, B. Solnica (Jagiellonian University, Krakow); the Netherlands - H.H.P.J. Lemkes, J.C. Lemkes-Stuffken (Leiden University Medical Center, Leiden); Portugal —J. Nunes-Correa, M.C. Rogado, L. Gardete-Correia, M.C. Cardoso, A. Silva, J. Boavida, M. Machado Sa Marques (Portuguese Diabetic Association, Lisbon); Luxembourg G. Michel, R. Wirion, S. Cardillo (Centre Hospitalier, Luxembourg City); France - B. Soussan, O. Verier-Mine, P. Fallas, M.C. Fallas (Centre Hospitalier de Valenciennes, Valenciennes); G. Cathelineau, A. Bouallouche, B. Villatte Cathelineau (Hospital Saint-Louis, Paris); United Kingdom - J.H. Fuller, J. Holloway, L. Asbury, D.J. Betteridge (University College London, London); J.D. Ward, S. Tesfaye, S. Eaton, C. Mody (Royal Hallamshire Hospital, Sheffield); S. Walford, J. Sinclair, S. Hughes, V. McLelland, J. Ward (New Cross Hospital, Wolverhampton); Austria - K. Irsigler, H. Abrahamian (Hospital Vienna-Lainz, Vienna); Croatia - G. Roglic, Z. Metelko, Z.R. Pepeonik (Vuk Vrhovac Institute for Diabetes, Zagreb); Romania - C. Ionescu-Tirgoviste, A. Coszma, C. Guja (Clinic of Diabetes, Nutrition \& Metabolic Diseases, Bucharest); Coordinating center - J.H. Fuller, N. Chaturvedi, J. Holloway, D. Webb, L. Asbury, M. Shipley, S.J. Livingstone (University College London, London); Central laboratories - G.-C. Viberti, R. Swaminathan, P. Lumb, A. Collins, S. Sankaralingham (Guy's and St. Thomas' Hospital, London).

REFERENCES

1. Vinik AI, Park TS, Stansberry KB, Pittenger GL. Diabetic neuropathies. Diabetologia 2000;43:957-73.

2. The Diabetes Control and Complications Trial Research Group. The effect of intensive diabetes therapy on the developmen and progression of neuropathy. Ann Intern Med 1995;122:561-8.

3. Microvascular and acute complications in IDDM patients: the EURODIAB IDDM Complications Study. Diabetologia 1994; 37:278-85.

4. Siedel J, Hagele EO, Ziegenhorn J, Wahlefeld AW. Reagent for the enzymatic determination of serum total cholestero with improved lipolytic efficiency. Clin Chem 1983;29:1075-80.

5. Bucolo G, David H. Quantitative deter mination of serum triglycerides by the use of enzymes. Clin Chem 1973;19:476-82.

6. Warnick GR, Albers JJ. A comprehensive evaluation of the heparin-manganese precipitation procedure for estimating high density lipoprotein cholesterol. J Lipid Res 1978; 19:65-76.

7. Friedewald WT, Levy RI, Fredrickson DS. Estimation of the concentration of lowdensity lipoprotein cholesterol in plasma, without the use of the preparative ultracentrifuge. Clin Chem 1972;18:499-502.

8. John WG, Gray MR, Bates DL, Beacham JL. Enzyme immunoassay: a new technique for estimating hemoglobin $\mathrm{A}_{1 \mathrm{c}}$. Clin Chem 1993;39:663-6.

9. Chaturvedi N, Sjoelie AK, Porta M, et al. Markers of insulin resistance are strong risk factors for retinopathy incidence in type diabetes. Diabetes Care 2001;24:284-9.

10. Kearney EM, MountJN, Watts GF, Slavin BM, Kind PRN. Simple immunoturbidimetric method for determining urinary albumin at low concentrations using Cobas-Bio centrifugal analyser. J Clin Pathol 1987;40:465

11. Aldington SJ, Kohner EM, Meuer S, Klein R, Sjolie AK. Methodology for retina photography and assessment of diabetic retinopathy: the EURODIAB IDDM Complications Study. Diabetologia 1995;38:437-44.

12. Rose GA, Blackburn H, Gilum RF, Prineas RJ, eds. Cardiovascular survey methods. 2nd ed. Geneva: World Health Organization, 1982.

13. Williams KV, Erbey JR, Becker D, Arslanian S, Orchard TJ. Can clinical factors estimate insulin resistance in type 1 diabetes? Diabetes 2000;49:626-32.

14. Ford I, Malik RA, Newrick PG, Preston FE, Ward JD, Greaves M. Relationships beween haemostatic factors and capillary morphology in human diabetic neuropathy. Thromb Haemost 1992;68:628-33.

15. Wiles PG, Pearce SM, Rice PJS, Mitchell JMO. Vibration perception threshold: influ- ence of age, height, sex, and smoking, and calculation of accurate centile values. Diabet Med 1991;8:157-61.

16. The Consensus Committee of the American Autonomic Society and the American Academy of Neurology. Consensus statement on the definition of orthostatic hypotension, pure autonomic failure, and multiple system atrophy. Neurology 1996;46: 1470.

17. Tesfaye S, Stevens LK, Stephenson JM, et al. Prevalence of diabetic peripheral neuropathy and its relation to glycaemic control and potential risk factors: the EURODIAB IDDM Complications Study. Diabetologia 1996;39:1377-84

18. Chaturvedi N, Bandinelli S, Mangili R, Penno G, Rottiers RE, Fuller JH. Microalbuminuria in type 1 diabetes: rates, risk factors and glycemic threshold. Kidney Int 2001;60: 219-27.

19. Maser RE, Steenkiste AR, Dorman JS, et al. Epidemiological correlates of diabetic neuropathy: report from Pittsburgh Epidemiology of Diabetes Complications Study. Diabetes 1989;38:1456-61.

20. Franklin GM, Kahn LB, Baxter J, Marshall JA, Hamman RF. Sensory neuropathy in non-insulin-dependant diabetes mellitus: the San Luis Valley Diabetes Study. Am J Epidemiol 1990;131:633-43.

21. Forrest KY, Maser RE, Pambianco G, 
Becker DJ, Orchard TJ. Hypertension as a risk factor for diabetic neuropathy: a prospective study. Diabetes 1997;46:665-70. 22. Young MJ, Boulton AJM, MacLeod AF, Williams DR, Sonksen PH. A multicentre study of the prevalence of diabetic peripheral neuropathy in the United Kingdom hospital clinic population. Diabetologia 1993;36: 150-4.

23. Forsblom CM, Sane T, Groop PH, et al. Risk factors for mortality in Type II (noninsulin-dependent) diabetes: evidence of a role for neuropathy and a protective effect of HLA-DR4. Diabetologia 1998;41:1253-62. 24. Coppini DV, Bowtell PA, Weng C, Young PJ, Sonksen PH. Showing neuropathy is related to increased mortality in diabetic patients - a survival analysis using an accelerated failure time model. J Clin Epidemiol 2000;53:519-23.

25. Gadia MT, Natori N, Ramos LB, Ayyar DR, Skyler JS, Sosenko JM. Influence of height on quantative sensory, nerve-conduction, and clinical indices of diabetic peripheral neuropathy. Diabetes Care 1987;10: 613-6.

26. Mitchell BD, Hawthorne VM, Vinik AI
Cigarette smoking and neuropathy in diabetic patients. Diabetes Care 1990;13:434 7.

27. Harris M, Eastman R, Cowie C. Symptoms of sensory neuropathy in adults with NIDDM in the U.S. population. Diabetes Care 1993;16:1446-52.

28. Dyck PJ, Davies JL, Wilson DM, Service EJ, Melton LJ III, O'Brien PC. Risk factors fo severity of diabetic polyneuropathy: intensive longitudinal assessment of the Rochester Diabetic Neuropathy Study cohort. Diabetes Care 1999;22:1479-86.

29. Cameron NE, Eaton SE, Cotter MA, Tesfaye $\mathrm{S}$. Vascular factors and metabolic interactions in the pathogenesis of diabetic neuropathy. Diabetologia 2001;44:1973-88.

30. Tesfaye S, Harris N, Jakubowski J, et al. Impaired blood flow and arterio-venous shunting in human diabetic neuropathy: a novel technique of nerve photography and fluorescein angiography. Diabetologia 1993; 36:1266-74

31. Eaton SE, Harris ND, Ibrahim S, et al. ncreased sural nerve epineurial blood flow in human subjects with painful diabetic neuropathy. Diabetologia 2003;46:934-9.
32. DeFronzo RA, Hendler R, Simonson D. Insulin resistance is a prominent feature of insulin-dependent diabetes. Diabetes 1982; 31:795-801.

33. Soedamah-Muthu SS, Chaturvedi N, Toeller M, et al. Risk factors for coronary heart disease in type 1 diabetic patients in Europe: the EURODIAB Prospective Complications Study. Diabetes Care 2004;27: 530-7.

34. Erbey JR, Robbins D, Forrest KY, Orchard TJ. Low-density lipoprotein particle size and coronary artery disease in childhood-onset type 1 diabetes population. Metabolism 1999;48:531-4. [Erratum, Metabolism 1999;48:1337.]

35. Zenere BM, Arcaro G, Saggiani F, Rossi , Muggeo M, Lechi A. Noninvasive detection of functional alterations of the arterial wall in IDDM patients with and without microalbuminuria. Diabetes Care 1995;18: 975-82.

36. Witte DR, Tesfaye S, Chaturvedi N, et al. Risk factors for cardiac autonomic neuropathy in Type 1 diabetes mellitus. Diabetologia (in press).

Copyright @ 2005 Massachusetts Medical Society.

ELECTRONIC ACCESS TO THE JOURNAL'S CUMULATIVE INDEX

At the Journal's site on the World Wide Web (www.nejm.org), you can search an index of all articles published since January 1975 (abstracts 1975-1992, full text 1993-present). You can search by author, key word, title, type of article, and date. The results will include the citations for the articles plus links to the full text of articles published since 1993. For nonsubscribers, time-limited access to single articles and 24-hour site access can also be ordered for a fee through the Internet (www.nejm.org). 